\title{
Scaling up Nigeria's Midwives Service Scheme and Reducing Inequality Gaps in Maternal Mortality
}

\author{
Emmanuel Onyebuchi Onugha \\ St. Camillus Catholic Hospital, Uromi, Nigeria \\ Email: emmanuel.onugha1@yahoo.com
}

How to cite this paper: Onugha, E.O. (2017) Scaling up Nigeria's Midwives Service Scheme and Reducing Inequality Gaps in Maternal Mortality. Open Journal of Obstetrics and Gynecology, 7, 880-896.

https://doi.org/10.4236/ojog.2017.78089

Received: July 19, 2017

Accepted: August 12, 2017

Published: August 15, 2017

Copyright $\odot 2017$ by author and Scientific Research Publishing Inc. This work is licensed under the Creative Commons Attribution International License (CC BY 4.0).

http://creativecommons.org/licenses/by/4.0/

c) (i) Open Access

\begin{abstract}
The Federal Government of Nigeria in December 2009 launched midwives service scheme to address the shortage of skilled healthcare workforce needed to drive the efforts at improving maternal and infant health, towards the attainment of MDGS 4 and 5. This was in response to the unrelenting increase in maternal mortality in Nigeria. This review explores the implementation of the scheme and the extent to which its set-goals are achieved vis-à-vis many challenges confronting it. The review first explores the ecologic perspective on maternal mortality to identify factors responsible for high mortality among Nigerian women and the inequality gaps in maternal mortality. The review identifies the need to scale up midwives service scheme to areas in dire health needs, identifies the need for health needs assessment, and recognizes community participation as an essential ingredient in ensuring the sustainability of midwives service scheme. Routine evaluation of midwives service scheme is identified as an important tool for assessing the effectiveness of the scheme in achieving its objectives towards improvement in maternal health and reduction in inequality gaps in maternal mortality. The review proposes multi-sectoral interventions in tackling inequality gaps in maternal mortality with strategic focus on addressing inequalities in health and social determinants of health.
\end{abstract}

\section{Keywords}

Midwives Service Scheme, Maternal Mortality, Inequality, Nigeria

\section{Introduction}

Maternal mortality (MM) is a major health issue in Nigeria which has one of the highest numbers of deaths per 100,000 live births in the world, with 545 deaths 
per 100,000 live births due to maternal causes [1]. MM is maternal death due to complications of pregnancy, complicated labour and puerperium, or due to omission, incorrect treatment or interventions; or maternal death due to intrinsic diseases co-existing with pregnancy [2]. MM may also be defined as pregnant woman's death at any time between conception and six weeks postpartum or due to abortion [3]. About 1 out of 15 Nigerian women die due to pregnancy complications and child birth, as against one death out of 5000 women in the developed world [4]. MM varies across the geopolitical zones of the country. The South West region recorded a low MM ratio (MMR) of 165 per 100,000 live births compared to 1549 per 100,000 live births in the North East [5]. MM is highest in the North West and the North East [6]. In developing countries, maternal deaths are caused by unsafe abortion, prolonged labour, postpartum hemorrhage, obstructed labour, infections and eclampsia [7], with $62 \%$ of these deaths caused by infections, toxemia of pregnancy and abortion complications [8]. Postpartum hemorrhage $(\mathrm{PPH})$ is excessive vaginal bleeding of more than $500 \mathrm{mls}$ which occurs within the first 24 hours or between 24 hours and 6 weeks following vaginal delivery [9]. About $44 \%$ of maternal deaths in the North of the country are caused by postpartum hemorrhage, with 1 out of every 6 women dying in the North East and North West while 1 out of 18 die in the South West and South East [6]. PPH is a major cause of MM in Nigeria and though predictable, preventable and treatable, it contributes significantly to high MM burden in the country. It is estimated that of all the births in Nigeria, 39\% occur with no help from health workers which may lead to high MM [6]. Gender disparity in school enrolment, power and income disparities, ethnicity and rural/urban location factors contribute significantly to the ever-widening inequality gaps in MM. The Nigerian government launched midwives service scheme (MSS) in December 2009, administered by National Primary Healthcare Development Agency (NPHCDA) to complement efforts at improving maternal and child health, and closing inequality gaps in MM. There is abundant literature on the impact of MSS on child and maternal mortality including challenges of MSS implementation, but little relating to the widening inequality gaps in MM and the need to scale up MSS and reduce the gaps. This article aims to examine the attributes of MSS in addressing inequalities in maternal mortality in Nigeria. It starts by discussing the ecologic perspective on high maternal mortality in Nigeria, the health needs assessment of communities being considered for MSS, the challenges facing MSS in addressing inequality gaps in MM, evaluation of MSS services and the strategies to scaling up MSS and reducing the identified inequality gaps.

\section{Ecologic Perspective on High MM in Nigeria}

The poor maternal health indices in the country can be traced back to the colonial period during which the Nigerian health system was systematically weakened with elitist health policies of the colonial masters [2]. These policies favoured establishment of urban-based hospitals and practice of curative instead 
of preventive medicine [2], and therefore excluded majority of Nigerians who lived in rural areas. As a result, only the privileged few had access to health facilities as most rural dwellers had little access to good quality healthcare. This gave rise to health inequalities between the poor and the rich, the urban and rural dwellers and across socio-economic groups. Unfortunately, this was the type of health system bequeathed to Nigerians by the colonial masters, which has persisted as evidenced by prevailing weak health system, skewed distribution of hospitals in favor of urban centres and high popularity of curative care. Public policies of the colonial masters supported the establishment of health facilities in selected areas without considering the needs of the people or promoting public participation in policy making process [2]. These policies impacted negatively on the health of most rural dwellers and the less privileged and fell short of strengthening families, neighborhoods, churches, voluntary organizations and social networks referred to as "mediating structures" [10].

Mediating structures have great influence on individual beliefs, lifestyles, health-related behaviors, societal norms and values, and connect individuals to the larger society [10]. For example, a pregnant woman's ability to access antenatal care is dependent on family's influence. In some Nigerian communities, early marriage is common while boys' education takes precedence over girls' education leading to low level of education among girls. Also, failure to go to school may be caused by early marriage and vice versa. In either case, early or unwanted pregnancy may occur which may lead to complications or death. Female adolescents may have little or no knowledge of family planning because the society frowns at family planning, erroneously believed to be related to promiscuity. This may translate to unwanted pregnancies, unsafe abortions, ignorance or inadequate information about danger signs of pregnancy and labour, which may lead to delay in seeking health care or adequately preparing for emergencies [6]. Evidence shows that early marriage causes $23 \%$ of maternal mortality due to pregnancy-related hemorrhage [6]. Also, in rural areas, home delivery is commonly practiced, mostly but unfortunately by unskilled birth attendants, which often leads to complications and maternal mortality [6]. Similarly, Female Genital Mutilation (FGM), a cultural practice in most Nigerian societies has been documented to cause PPH and maternal death. For example, FGM may cause scar tissue formation which may not stretch well during vaginal delivery leading to possible perineal laceration and bleeding. Therefore to elicit changes in individuals' healthseeking behaviours, the support of the community mediating and power structures must be solicited [10].

Further, the question of the influence of organizational processes on maternal health and health-related behaviors is as important. Organizations are vital sources of social norms and values which are transmitted through socialization and acculturation [11]. Organizations such as schools, work settings, neighborhood associations, professional bodies, churches and mosques may serve as important mediating structures between individuals and the larger society with profound positive and/or negative effects on members' health [10]. Family planning, for 
example, is forbidden by some religious organizations while some others encourage early marriage. Some organizational policies may make it difficult for pregnant staff to access all required ante-natal sessions. For example, excessive workload in a work setting with little time for proper personal care may limit antenatal visits and jeopardize the safety of a pregnant worker, or it may cause stress and possible threat to the pregnancy. In addition, some private organizations do not make adequate provision for maternity leave that will give enough time for staff members to take good care of their health and that of their new born babies. Above all, organizations provide an easy access to groups of people and the opportunity to build social support [10]. In workplaces, for example, management support, incentives and changes in work structure, benefits and regulations are organizational characteristics that can be used to improve maternal health. Therefore, organizational change must be targeted during efforts to reduce inequality gaps in MM. Organizational change is an important component of organizational culture which is highly supportive of health issues, but more importantly a prerequisite for adopting, implementing and institutionalizing health promoting initiatives [10]. This is relevant in reducing maternal mortality and improving maternal health via MSS. Related to this are interpersonal factors which influence health-seeking behaviors of individuals.

Interpersonal relationships with neighbors, friends, family members, acquaintances and contacts at work will determine whether or not a pregnant woman will visit a doctor for non-emergency purposes and the timing of such visits. This is corroborated by McLeroy et al. [10]. How a pregnant woman copes with stress; her health seeking behavior; the risk of an adolescent getting pregnant [12]; her ability to cope with the pregnancy; and the morbidity and mortality risks are all affected by social relationships [10]. The impact of interpersonal relationships on maternal health cannot be overemphasized. An adolescent's risk of pregnancy may be influenced by families and sexual partners. The age at which sexual activity is initiated by an adolescent girl has a direct relationship with the age at which sexual intercourse is initiated by her mother [10]. An adolescent girl whose mother or siblings became pregnant in their teens is more likely to become pregnant in her teens, and adolescent girls with sexually active friends are more likely to be sexually active [10]. Also, evidence shows that families and peers influence the possibility of early pregnancy [10]. Therefore, there is need to incorporate interventions like family support programmes, skills training, developing norms for the use of contraceptives in male adolescent networks and support groups as part of MSS with the aim of modifying the social environment. Further, intrapersonal factors including individual attitudes, knowledge, skills, self-concept and behavior lie within the individual instead of the social environment and affect health related behaviors. In a country like Nigeria where more than $50 \%$ of the population are not able to read and write [13] and where majority of the people live below poverty line [14], it may be difficult to make a pregnant woman, her family members and/or relatives appreciate the need for 
non-emergency visits to the physician. In some rural areas, many women do not see any need for a pregnant woman to go to a health facility for Ante-Natal Care (ANC) until the third trimester, unless there is a complication. They argue that pregnancy should be allowed to progress on its own with minimal hospital visits. Also, many people are more disposed to patronizing traditional and/or spiritual healers or unskilled birth attendants during pregnancy than attending ANC clinics or seeing the doctor. Therefore, attitudinal change model such as the health belief model [15] can be used to explain health related behaviors of individuals that contribute to high MMR in Nigeria. Intervention at this level is aimed at changing individuals. According to Steckler [16], the distinction between practice units (the theory underlying inequality gaps in MM due to $\mathrm{PPH}$ ) and the solution units (the intervention levels) helps in understanding the ecologic strategies. Intervention at the intrapersonal level requires the use of intervention levels such as mass media, educational programmes, support groups, peer counseling or organizational incentives in addition to targeting individual characteristics such as knowledge, skills and attitudes [10].

\section{Health Needs Assessment}

The MSS should be scaled up to areas lacking or needing more of its services using PRECEDE/PROCEED framework of health programme planning [17] (Figure 1) to assess and understand the communities in need of MSS and how best it can be tailored to their needs.

PRECEDE/PROCEED model is relevant in planning interventions to reduce MM due to PPH. It assesses multiple health determinants such as organizational, environmental, predisposing, reinforcing and enabling factors influencing health

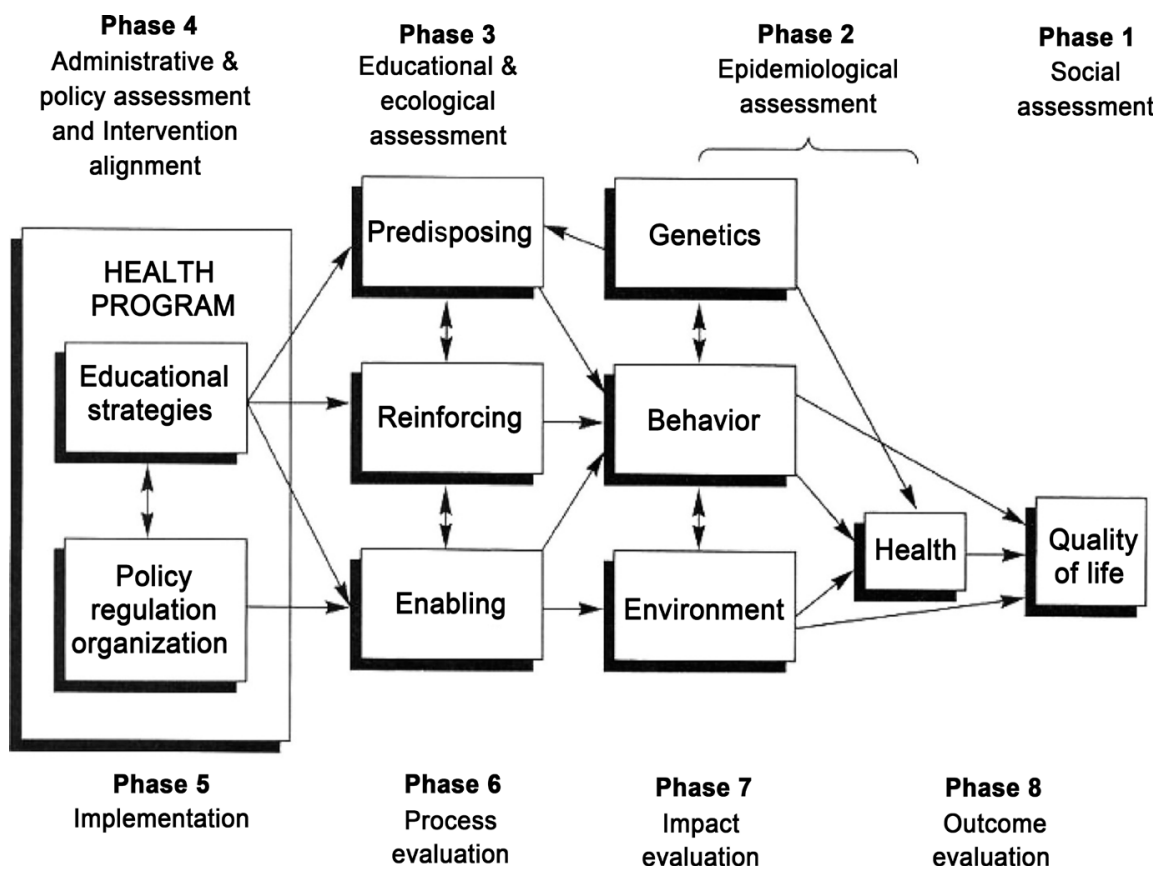

Figure 1. PRECEDE-PROCEED framework of health programme planning [17]. 
behaviors and health service utilization [18]. Targets are identified and prioritized for interventions through an assessment process that occurs in phases such as social assessment (phase 1), epidemiologic assessment (phase 2), behavioral and environmental assessment (phase 3), educational and ecological assessment (phase 4) and administrative and policy assessment (phase 5) [17]. Social assessment is done through observations, surveys, interviews or focus groups to understand a community's social characteristics, strengths, ability to solve problems and adapt to change; and to identify available resources, existing gaps, and obstacles to achieving good maternal and child health. A community's needs and desires are articulated and a strong partnership established to ensure full participation in MSS implementation. With community mobilization, factors influencing health behaviors can be changed. Epidemiological assessment using vital statistics such as Demographic and Health Survey (DHS) and other documentary evidence will identify the behavioral, socio-economic, cultural and environmental factors responsible for inequality gaps in MM. Such factors may include but not limited to patronage of spiritual healers by pregnant women, non-appreciation of the importance of non-emergency visits to physicians, influence of other people's beliefs and behaviors as exemplified by interpersonal relationship; and factors such as weak health system, inaccessible and unaffordable healthcare services, inadequate healthcare facilities, poor education, unemployment, poor working condition and absence of good road networks all of which contribute significantly to high MM in Nigeria. At the individual level, educational and ecological assessment will examine the predisposing or motivating factors such as attitudes, beliefs, skills and knowledge which influence a particular behavior [17]. Similarly, at the level of interpersonal relationship, incentives (or reinforcing factors) such as family/peer influence and social support which perpetuate a behavior are assessed, while at the community level, enabling factors such as resources, skill development, provision of health facilities, adequate manpower, and improved MSS services are put in place to enable behavior change [17]. During policy assessment and intervention alignment, the above factors are prioritized in terms of their severity or the extent of their contribution to high MM and their changeability. This in turn is dependent on appropriate policy framework for MSS implementation, available resources, and organizational facilitators and barriers. In scaling up MSS, this article identifies a number of strategies including matching the scheme to the ecological levels (intrapersonal, interpersonal, organizational and community), mapping of interventions based on identified predisposing, reinforcing and enabling factors, pooling of similar previous programme (s), applying lessons learnt from previous work/studies, and directing specific interventions at identified gaps. This article proposes a combination of these strategies.

\section{MSS Challenges in Addressing Inequality Gaps in MM}

Midwives play a key role as skilled attendants in taking normal deliveries. Un- 
fortunately in Nigeria, the presence of skilled attendants in ANC sessions is 58\% while it is only $39 \%$ during childbirth [19]. This contributes immensely to the poor health outcomes of pregnant women in Nigeria. Also, there is shortage of health workers, and a lot of challenges in attracting and retaining the right mix of health workers in rural areas, partly because of prevailing disincentives such as poor electricity supply, inadequate water supply, lack of opportunities for career development and excess workload. Part of the reasons for designing MSS programme is to address the shortage of health workers at the level of primary health care. MSS health workforce comprises newly trained midwives, unemployed, and retired midwives who are interested in joining the service. They go through refresher courses to develop and improve on emergency obstetric care skills, and thereafter get posted to underserved areas [6]. The trained midwives get deployed to primary health centres (PHC) spread across the country where they are empowered with drugs, family planning commodities, midwifery kits and basic equipment to provide maternal and child health $(\mathrm{MCH})$ services [20]. About 4000 midwives are currently engaged under the scheme involving 1000 PHCs in rural communities, with 4 midwives posted to each PHC [20]. PHCs are placed in clusters, with each cluster comprising 4 PHCs that are linked to a referral general hospital [20]. While in service, midwives receive further training in integrated management of childhood illnesses and life-saving skills, and get information technology support in the form of internet access, video conferencing and toll-free mobile phones which enhance their communication with colleagues and pregnant women, leading to improved quality of healthcare [4]. Targets were set for MSS to achieve improved ANC attendance by pregnant women, increased contraception uptake, increase in the number of PHCs providing basic emergency obstetric care and MHC services managed by qualified midwives, improved skilled birth attendance, and reduction in maternal and child mortality [21]. Some modest successes were recorded following increased ANC visits, increase in the number of women receiving tetanus toxoid doses, increased facility-based deliveries, and reduction in the MMR and neonatal mortality ratio [4]. MSS is funded from savings from the debt relief granted Nigeria by the Paris Club [6] and savings from partial subsidy removal under the subsidy reinvestment programme [22]. The workers are paid monthly allowance by the federal government, while the state and local governments together pay transport allowance, rural posting allowance, in addition to the provision of free accommodation for the workers. However, many state and local governments fail to provide their counterpart funding of the scheme [5]. It may be argued that the sustainability of MSS is in doubt because it is a top-bottom approach without active participation by community members [4]. Also, incentives are not enough to keep midwives motivated as they complain of delayed salary and poor accommodation [4], and their inability to freely demonstrate their expertise because of the constraints placed by other cadres of health workers in charge of their places of assignment [6]. Further, though measures such as provision of customized 
drugs, regular monitoring and evaluation of the performance of MSS, and centralization of supply chain and management, among others, were put in place to reduce abuses and theft, corruption is so deep that some of the free drugs, for example, still find their way in the open market [6]. Though the scheme has succeeded in reducing MM as evidenced by reduction in MMR from 789 per 100,000 prior to the commencement of the scheme to 572 per 100,000 live births in 2010 [5], it is obvious that more needs to be done.

\section{Evaluating MSS Programme}

Evaluation is an important aspect of MSS services as it helps to assess the worth and value of the scheme. There is need to assess how resources are used, whether the success recorded is commensurate with the resources deployed, how worthwhile the scheme is, the impact on the people, how relevant and adequate the intervention delivery is, and the overall benefits [18]. Using Maxwell's evaluation criteria [23], MSS effectiveness will be evaluated by assessing the percentage of pregnant women who enrolled in ANC class, completed their ANC sessions and had safe delivery and postpartum period. Also, irrespective of the level of available resources, efficiency will ensure there is improved enrolment of pregnant women into ANC programmes and successful delivery with good health outcome. Similarly, there is need to ensure equitable service provision by ensuring that same attention and quality of services are provided to every pregnant woman such that all stable clients have equal waiting time and none is discriminated against. Determining the responsiveness of MSS to the target groups through patient satisfaction surveys will help throw light on how appropriate MSS is in meeting client needs, reducing infant and maternal mortality, and improving the quality of obstetric care. The acceptability of MSS can be assessed through patient satisfaction surveys on issues like level of communication and relationship with health workers, privacy and other concerns they may have. Finally, the accessibility of services can be measured by looking at the time taken by the clients to reach the nearest health center, and turn-around time for each client during hospital visits, for example, the time a case file is issued to the time a client departs the health facility. All the information as required above can be obtained from hospital records and surveys.

In addition, a logical framework should be developed and contextualized at every service point of MSS across all the PHCs in the country to outline the programme's goals, inputs, activities, barriers to programme implementation, outputs and expected outcomes. Logical framework (LF) is a quality management tool to identify problems, derive solutions and provide a planning matrix for programme implementation and evaluation of performance [24]. Stakeholders including representatives of communities should be involved in developing an LF. The effectiveness of LF in quality management and delivery of healthcare services is not in doubt as exemplified by its successful application in many donor-funded projects [24] [25] [26] and hospitals [27]. LF is criticized for being 
too linear and narrow, ignoring the impact of externalities and unintended outcomes on a programme. It is also criticized for being more theoretical than pragmatic in practice [28]. However, LF will improve the quality of MSS services delivery by identifying the real problems and suggesting practical and cost-effective solutions. For example, it addresses barriers to satisfactory performance of MSS such as inadequate infrastructure (e.g. inadequate equipment, drugs, inadequate pre-hospital services, and improper communication infrastructure), delay in consultation due to inadequate number of health workers, lack of commitment and poor or lack of motivation etc. Below (Table 1) is an example of an MSS Logical Framework.

\section{Recommendations}

It is important to note that for a country like Nigeria which has weak health sys-

Table 1. Example of an MSS logical framework.

\begin{tabular}{|c|c|c|c|}
\hline Objective & Indicators & $\begin{array}{c}\text { Means of } \\
\text { Verification }\end{array}$ & Assumptions \\
\hline $\begin{array}{l}\text { Goal } \\
\text { 1) Increase in the use of MSS services by } \\
\text { women. }\end{array}$ & $\begin{array}{l}\text { Increase in the number of women using MSS } \\
\text { services from ... in base year to ... }\end{array}$ & $\begin{array}{l}\text { Health facility } \\
\text { records }\end{array}$ & $\begin{array}{l}\text { Unavailability of } \\
\text { equivalent alternative. }\end{array}$ \\
\hline $\begin{array}{l}\text { Purpose } \\
\text { 1) Prompt medical attention. } \\
\text { 2) Reduction in adverse client outcome. }\end{array}$ & $\begin{array}{l}\text { Reducing waiting/treatment time from .... in } \\
\text { base year to ... } \\
\text { Reducing incidence of adverse client outcome } \\
\text { from ... in base year to ... }\end{array}$ & $\begin{array}{l}\text { Health facility } \\
\text { records }\end{array}$ & \\
\hline $\begin{array}{l}\text { Outputs } \\
\text { 1) Availability of midwives and support staff } \\
\text { for services. } \\
\text { 2) Adequate infrastructure. } \\
\text { 3) Proper triaging. } \\
\text { 4) Effective handling and disposal of clients. }\end{array}$ & $\begin{array}{l}\text { Increase in the number midwives and support } \\
\text { staff from ... in base year to ... } \\
\text { Increase in the satisfaction of midwives and } \\
\text { support staff from ... in base year to ... } \\
\text { Reduction of adverse client outcome due to } \\
\text { infrastructure inadequacy from ... in base year } \\
\text { to ... } \\
\text { Triaging effectiveness improves from ... in base } \\
\text { year to ... }\end{array}$ & $\begin{array}{l}\text { Health facility } \\
\text { records, } \\
\text { satisfaction } \\
\text { survey reports }\end{array}$ & $\begin{array}{l}\text { Availability of technology, } \\
\text { materials and resources for } \\
\text { MSS. Efficient functioning of } \\
\text { units like infection control, } \\
\text { wards, pharmacy etc. } \\
\text { Commitment of health } \\
\text { facility management to } \\
\text { excellence. }\end{array}$ \\
\hline $\begin{array}{l}\text { Inputs } \\
\text { 1) Develop policy for recruitment of midwives } \\
\text { and other health providers. } \\
\text { 2) Put in place system for fair salary structure, } \\
\text { promotion and reward. } \\
\text { 3) Improve working conditions. } \\
\text { 4) Promote team work. } \\
\text { 5) Put in place method for appropriate } \\
\text { triaging. } \\
\text { 6) Produce a list of related functions with } \\
\text { other units that affect client handling and } \\
\text { disposal, and improve these functions. } \\
\text { 7) Provide efficient pre-health facility services. } \\
\text { 8) Purchase and maintain emergency obstetric } \\
\text { care equipment. } \\
\text { 9) Inspect and maintain health facilities. } \\
\text { 10) Develop communication infrastructure. }\end{array}$ & Budget & $\begin{array}{l}\text { Budget } \\
\text { documents }\end{array}$ & $\begin{array}{l}\text { Availability of fund. Effective } \\
\text { planning, execution and } \\
\text { control of MSS activities. } \\
\text { Clear policy on recruitment, } \\
\text { promotion, salary structure } \\
\text { and incentives for midwives } \\
\text { and other health providers. }\end{array}$ \\
\hline
\end{tabular}


tem, weak institutions and weak policies, multi-sectoral interventions are needed to improve maternal health. These interventions must cut across households, communities, health and other sectors vis-à-vis their impact on maternal health outcomes. Interventions at the health system level will include development of policies that will financially protect the poor, ensure responsiveness to client expectations and promote provision of culturally appropriate services [29]. Policies must stipulate clear regulatory and enforcement mechanisms for ensuring quality of healthcare services. Political commitment must be demonstrated while policies that engender equal rights for women in areas of education, employment and voting must be developed [29]. Emphasis must be placed on critically underserved areas in terms of policy direction and resource allocation. Worthy of emulation is Honduras' example, where MM reduction initiative established by the government reduced maternal mortality rate from 182 to 108 per 100,000 women within a period of 7 years. This was achieved with the ministry of health investing heavily in the development of infrastructure particularly in areas with high MM [30]. The capacity of health workers was also developed resulting in an improvement in the quality of health services, while community members participated actively in building birthing centres and maternity waiting rooms [30]. Community participation in MSS helps to promote health and behavioral change by creating an enabling environment for pregnant women and relatives to easily adopt healthy lifestyles and health-seeking behavior. In Bangladesh, a community-based health programme that saw traditional birth attendants collaborating with primary health care workers resulted in reduction in birth rates and an increase in uptake of immunization and contraceptives [31]. Community-driven initiatives have been confirmed to improve maternal health by increasing access to community health insurance [32], uptake of contraceptives [33] and health care knowledge [34].

In addressing shortage of health workforce in rural Nigeria which is hindering the smooth implementation of MSS, lessons should be drawn from similar interventions in other countries that impacted positively on the health status of their citizenry. The concept of the Barefoot Doctors emerged in China in 1968 and was aimed to reduce the inequality gaps in access to health care in Chinese rural areas [35]. The Barefoot Doctors were made up of young farmers trained in medicine over 3 to 6 months to provide sustainable health care services in their communities [36]. This intervention was described as culturally and economically feasible [37]. Though it was government led with strong political commitment, it was decentralized, culture-sensitive, egalitarian, and it helped to improve access to health care and reduce particularly infant and maternal mortality in rural China [38]. This strategy contributed immensely to Chinese success of reducing MM from 150 per 100,000 live births prior to 1949 to 41.3 per 100,000 live births [38]. In Pakistan, community women were trained as lady health workers to provide certain level of healthcare services in rural areas as well as urban slums, in order to bridge the gap occasioned by the shortage of health workers in 
these areas [39]. Also, clinical officers were trained in Kenya and Mozambique to provide health care services to rural communities [40]. Worthy of note is the effort by the United Nations Population Fund (UNFPA) to provide training of Nigeria's community health extension workers across all 774 local government areas to empower them to provide health care services specifically targeted at improving maternal health [41]. This should be sustained.

Private and public health sectors must form a strong partnership in efforts to reduce MM. There is need for the government at all levels, the private sector and non-governmental organizations to increase access to family planning information and services. Nigerian government must ensure improved quality, increased coverage and uptake of prenatal care. Similarly, management of prenatal, antenatal and postnatal periods; and management of delivery and neonatal complications should be improved upon through adequate training and continuing professional development of health workers. Appropriate incentives must be provided to attract health workers to underserved rural and remote areas so that the level of skilled birth attendance during health facility and home deliveries will increase. There is need for collaboration between midwives and traditional birth attendants to provide an opportunity for promoting safe home deliveries. This can be done by the midwives seeking out the traditional birth attendants in their areas of assignment and establishing cordial relationship with them. Also, the government should provide more health centres and well trained health workforce across the 774 local government areas to enable them effectively provide essential health package that will include emergency obstetric care. Referral systems must be strengthened so that cases that cannot be handled at the primary healthcare level are promptly referred to the next level.

Policy makers should develop policies that promote multi-sectoral investments in telecommunication, roads, power and education of women which will help in improving access and uptake of health care services by women. There is evidence that investing in the education of women will result in an improvement in maternal health and a reduction in MM. Underscoring the importance of women empowerment and maternal health, Malaysia and Sri Lanka had deliberate policies directed at promoting female literacy [42] [43]. Also, evidence shows that timely access to health facilities is increased with good transportation networks and improved telecommunication system [44]. In Mali, communities with ambulances and improved radio communication system recorded increased emergency referral rates from $1 \%$ to $3 \%$ [29]. The role of safe drinking water and improved sanitation in promoting population health and by extension maternal health, through reduction in water-borne diseases, is well acknowledged. Similarly, intake of balanced diet, food supplement, treatment of intestinal worms and reduction in fertility rate are known to lead to an improvement in women's nutritional status [45].

Nigeria's health system needs to be strengthened by increasing health financing, utilizing resources effectively, developing infrastructure and reducing the 
cost of health care services, among other measures. This requires reforms in health service provision, resource generation, health financing, and capacity development [46]. It is believed that the newly promulgated National Health Act when fully implemented will address the myriads of challenges besetting Nigeria's health system. The Act aims to strengthen Nigeria's health system, promote professionalism, ensure universal health coverage, and delineate clear and specific functions for each tier of government [47]. It addresses the issue of health financing by creating a basic health care provision fund (BHCPF), 50\% of which will be utilized to fund National Health Insurance Scheme (NHIS) to provide health care services at primary and secondary levels of health care, $20 \%$ for procuring essential drugs, consumables and vaccines for all the PHCs in the country, 15\% for providing and maintaining transportation systems, facilities and equipment in PHCs, and $10 \%$ for building capacity in primary health care [48]. The BHCPF is to be financed annually with $1 \%$ of Nigerian government's consolidated revenue fund, money from international donors and other sources such as taxes [48]. The bill also makes provision to exempt certain categories of people such as older people, women, children and persons with disability from footing the bill of healthcare services they receive in public hospitals [48].

Strategies for quality improvement and management should be incorporated into clearly defined plan for health system reforms [49]. Policy makers should develop implementable quality care policies to provide guidelines on quality programmes across the country [49]. Also, Nigeria needs to develop the capacity of its health workers to respond effectively and efficiently to the health needs of its citizens which may require the hiring of qualified regional or local technical assistants who have adequate knowledge of local issues. Policies should be put in place to guide the use of technical assistance in capacity development in the country. More importantly, credible leadership and good governance are essential ingredients to successful implementation of MSS. Corruption, lack of accountability, favoritism, nepotism, healthcare staff absenteeism and fraud in procuring health commodities are cogs in the wheel of MSS progress. Corruption breeds poor health system performance including ineffective resource allocation, lack of drugs in health facilities, non-availability of medical equipment and medical supplies, unbalanced distribution of health workers, increase in the number of ghost workers and leakages in health budget. There is need to strengthen internal control mechanisms and institutions like the Independent and Corrupt Practices Commission and Economic and Financial Crime Commission to punish offenders and discourage corruption. The prevailing value system that respects rich people, irrespective of their sources of wealth, must give way to celebration of integrity and accountability.

Health workers with appropriate mix of skills are in short supply in Nigeria. Nigerian health workers migrate overseas or frequently change jobs because of lack of motivation and incentives. Most of them face long working hours, poor conditions of service, excess workloads, lack of supportive supervision, lack of opportunities for career development and poor remuneration [50]. There is need 
to consider the use of paid leave, wage increase, loan prospects, allowances, fellowships, maternity leave, flexibility in working time, study leave, housing and career breaks to attract midwives and other health workers to MSS. The 20082012 Nigeria's Human Resources for Health strategic plan, which provides guidelines on the hiring and posting of health workers as well as the use of incentives to attract and retain health workers [51], must be fully implemented. Policies should be put in place to encourage the training and motivation of more health workers who hail from rural areas and are committed to returning home to practise after graduation. Future research is needed to identify context-specific supplyand demand-side constraints to the uptake of MCH services provided by MSS, similar to the formative research currently underway in Ondo and Nasawara States Nigeria investigating low MHC service utilization in health facilities where performance based financing (PBF) programme is being implemented in order to inform intervention strategies targeting demand-side challenges [20]. Supplyand demand-side factors such as drugs availability, infrastructural development, incentives, motivation, transportation, costs, service valuation and programme awareness play an important role in determining MCH service utilization [52]. Future research should evaluate the effects of scaling up access to skilled obstetric care in order to capture specific health outcomes arising from the implementation of scaled up MSS.

\section{Conclusion}

The article highlights the need to improve the health of the most disadvantaged groups, narrow existing health gaps and reduce health gradients [53] across the Nigerian population in efforts to improve maternal health and reduce MM. The article advocates tackling social inequalities responsible for rising $\mathrm{MM}$ in Nigeria, with emphasis on reducing inequalities in broader determinants of health and in individual risk factors using "determinants-oriented approaches" [54]. This is expected to lead to a significant improvement in maternal and child health, and reduction in inequality gaps in maternal mortality in Nigeria.

\section{References}

[1] National Population Commission and ICF Macro (2009) National Population Commission, Nigeria and Macro. Nigerian Demographic and Health Survey 2008. Federal Republic of Nigeria, Abuja.

[2] Birn, A.-E., Pillay, Y. and Holtz, T. (2009) Textbook of International Health: Global Health in a Dynamic World. 3rd Edition, Oxford University Press, Oxford.

[3] WHO (1992) ICD-10: International Statistical Classification of Diseases and Related Health Problems, Tenth Revision and Updated Version for 2007. WHO, Geneva.

[4] Adogu, P. (2014) Midwifery and Midwives Service Scheme: A Panacea for Improvement of Some Maternal and Neonatal Indices in Nigeria-A Brief Review. Open Journal of Obstetrics and Gynecology, 4, 343-348. http://www.scirp.org/journal/PaperDownload.aspx?paperID $=45775$ https://doi.org/10.4236/ojog.2014.47051 
[5] Abimbola, S., Ooli, U., Olubajo, O., Abdullahi, M. and Pate, M. (2012) The Midwives Service Scheme in Nigeria. PLOS Medicine, 9, 1-5. https://doi.org/10.1371/journal.pmed.1001211

[6] Olusegn, O., Thomas, I. and Michael, I. (2012) Curbing Maternal and Child Mortality: The Nigerian Experience. International Journal of Nursing and Midwifery, 4, 33-39. http://www.academicjournals.org/IJNM

[7] Marchie, C. and Anyanwu, F. (2009) Relative Contributions of Socio-Cultural Variables to the Prediction of Maternal Mortality in Edo South Senatorial District, Nigeria. African Journal of Reproductive Health, 13, 109-115.

[8] Lindroos, A. and Lukkainen, A. (2004) Antenatal Care and Maternal Mortality in Nigeria. Public Health Programme-Exchange to Nigeria.

http://www.antenatal-Nigeria.pdf

[9] DeCherney, A., Goodwin, M., Nathan, L. and Laufer, N. (2007) Current Diagnosis \& Treatment, Obstetrics \& Gynecology. 10th Edition, International Edition, McGrawHill, New York.

[10] McLeroy, K.R., Bibeau, D., Steckler, A. and Glanz, K. (1988) An Ecological Perspective on Health Promotion Programs. Health Education Quarterly, 15, 351-377. http://journals.sagepub.com/doi/pdf/10.1177/109019818801500401

[11] Van Maanen, J. and Barley, S. (1985) Organizational Culture: Fragments of a Theory. In: Frost, P., Moore, L., Louis, M., Lundberg, C. and Martin, J., Eds., Organizational Culture, Beverly Hills, Sage, 31-53.

[12] Hofferth, S. (1987) Contraceptive Decision-Making among Adolescents. In: National Academy of Sciences, Risking the Future: Adolescent Sexuality, Pregnancy and Childbearing, Working Papers. National Academy Press, Washington DC. https://www.ncbi.nlm.nih.gov/books/NBK219233/

[13] Bakare, M. (2015) 65 Million Nigerians Are Illiterates-UNESCO. http://www.vanguardngr.com/2015/12/65-million-nigerians-are-illiterates-unesco/

[14] Nwabughiogu, L. (2015) Over 100m Nigerians Living Below Poverty Line-Osinbajo.

http://www.vanguardngr.com/2015/08/over-1-million-nigerians-living-below-pover ty-line-osinbajo/

[15] Janz, N. and Becker, M. (1984) The Health Belief Model: A Decade Later. Health Education Quarterly, 11, 1-48. https://doi.org/10.1177/109019818401100101

[16] Steckler, A. (1985) Implementing Change in Communities: A Collaborative Process. Health Education Quarterly, 12, 215-218. https://doi.org/10.1177/109019818501200208

[17] Green, L. and Kreuter, M. (2005) Health Program Planning: An Educational and Ecological Approach. 4th Edition, McGraw-Hill Higher Education, New York.

[18] Naidoo, J. and Wills, J. (2009) Assessing Health Needs. In: Naidoo, J. and Wills, J., Eds., Foundations for Health Promotion, 3rd Edition, Bailliere Tindall Elsevier, Edinburgh, 253-267.

[19] Nigeria Demographic Health Survey (2008) Countdown to 2015: Maternal, Newborn and Child Survival. Federal Republic of Nigeria, Abuja.

[20] National Primary Healthcare Development Agency (NPHCDA) (2017) Department of PHC Systems Development. https://www.nphcda.org/department-of-phc-systems-development/

[21] National Primary Healthcare Development Agency (NPHCDA) (2016) Making a Difference with the Midwives Service Scheme. 
https://www.nphcda.org/2016/03/01/making-a-difference-with-the-midwives-servic e-scheme/

[22] Nwosu, O. and Ugwuerua, E. (2014) Analysis of Subsidy and Reinvestment Programme (SURE-P) and Youth Empowerment in Nigeria 2012-2014. IOSR Journal of Humanities and Social Sciences, 19, 25-32.

[23] Maxwell, R. (1984) Quality Assessment in Health. British Medical Journal, 288, 1470-1472.

http://www.ncbi.nlm.nih.gov/pmc/articles/PMC1441041/pdf/bmjcred00500-0072.p df

[24] Dey, P., Hariharan, S. and Brookes, N. (2006) Managing Healthcare Quality Using Logical Framework Analysis. Managing Service Quality: An International Journal, 16, 203-222. https://doi.org/10.1108/09604520610650655

[25] Bornstein, L. (2003) Management Standard and Development Practices in South African Aid Chain. Public Administration and Development, 23, 393-404. https://doi.org/10.1002/pad.291

[26] MacArthur, J.D. (1993) The Logical Framework-A Tool for the Management of Project Planning and Evaluation. University of Bradford, Development and Project Planning Centre, Bradford.

https://bradscholars.brad.ac.uk/bitstream/handle/10454/4881/ID7098D\%20MACA RTHUR\%2042.pdf?sequence $=3$ \&isAllowed $=y$

[27] Harharan, S., Dey, P.K., Moseley, H.S.L., Kumar, A.Y. and Gora, J. (2004) A New Tool for Measurement of Process-Based Performance of Multispecialty Tertiary Care Hospitals. International Journal of Health Care Quality Assurance, 17, 302312. https://doi.org/10.1108/09526860410557552

[28] Bakewell, O. and Garbutt, A. (2005) The Use and Abuse of the Logical Framework Approach. http://www.mande.co.uk/docs/LFA\%20Review\%20final.doc

[29] Lule, E., Ramana, G., Ooman, N., Epp, J., Huntington, D. and Rosen J. (2005) Achieving the Millennium Development Goal of Improving Maternal Health: Determinants, Interventions and Challenges. World Bank, New York. http://siteresources.worldbank.org/HEALTHNUTRITIONANDPOPULATION/Res ources/281627-1095698140167/LuleAchievingtheMDGFinal.pdf

[30] Danel, I. and Rivera, A. (2003) Honduras, 1990-1997. In: Koblinsky, M., Ed., Reducing Maternal Mortality: Learning from Bolivia, China, Egypt, Honduras, Indonesia, Jamaica, and Zimbabwe, The World Bank, Washington DC, 51-62.

[31] Chowdhury, M. (1998) The Role of Traditional Birth Attendants in a Safe Delivery Programme in Bangladesh. Tropical Doctor, 28,104-106.

https://doi.org/10.1177/004947559802800219

[32] Wilson, K. (2002) The Role of Self-Help Group Bank Linkage Program in Preventing Rural Emergencies in India. The Seminar on SHG-Bank Linkage Program, World Bank, New Delhi, November 25-26, 1-86. http://services.iriskf.org/data/articles/Document13122006522.196902E-02.pdf

[33] Schuler, S.R., Hashemi, S. and Riley, A. (1997) The Influence of Women's Changing Roles and Status in Bangladesh's Fertility Transition: Evidence from a Study of Credit Programs and Contraceptive Use. World Development, 25, 563-575. https://doi.org/10.1016/S0305-750X(96)00119-2

[34] Hadi, A. (2001) Promoting Health Knowledge through Micro-Credit Programmes: Experience of BRAC in Bangladesh. Health Promotion International, 16, 219-227. https://doi.org/10.1093/heapro/16.3.219 
[35] Zhang, D. and Unschuld, P. (2008) Comment: China's Barefoot Doctor: Past, Present, and Future. The Lancet, 372, 1865-1867. https://doi.org/10.1016/S0140-6736(08)61355-0

[36] Valentine, V. (2005) Health for the Masses: China's Barefoot Doctors. http://www.npr.org/templates/story/story.php?storyId=4990242

[37] White, S.D. (1998) From "Barefoot Doctors to Village Doctors" in Tiger Springs Village: A Case Study of Rural Health Care Transformations in Social China. $\mathrm{Hu}$ man Organization, 57, 480-490.

http://www.iupui.edu/ anthkb/e445/readings/white.pdf https://doi.org/10.17730/humo.57.4.hp3311372h0xx2u7

[38] World Health Organization (n.d) China's Village Doctors Take Great Strides. http://www.who.int/bulletin/volumes/86/12/08-021208/en/

[39] World Health Organization (n.d) Country Case Study, Pakistani's Lady Health Workers Programme. Global Health Workforce Alliance.

http://www.who.int/workforcealliance/knowledge/case_studies/CS_Pakistan_web_e n.pdf?ua $=1$

[40] Wilson, B. (2005) Developing Countries See Health Care 'Brain Drain'. http://www.npr.org/templates/story/story.php?storyId=4987628

[41] Association for Reproductive and Family Health (2014) Increasing Access to Contraceptives in Nigeria through Task-Shifting to Community Health Extension Workers.

http://arfh-ng.org/increasing-access-contraceptives-nigeria-task-shifting-communit y-health-extension-workers-chews/

[42] Koblinsky, M., Campbell, O. and Heichelheim, J. (1999) Organizing Delivery Care: What Works for Safe Motherhood? WHO Bulletin, 11, 399-406.

[43] Pathmanathan, I., Liljestrand, J., Martins, J.M., Rajapaksa, L., Lissner, C., et al. (2003) Investing in Maternal Health: Learning from Malaysia and Sri Lanka (Health, Nutrition and Population Series). The World Bank, Health Development Network, Washington DC.

[44] Samai, O. and Sengeh, P. (1997) Facilitating Emergency Obstetric Care through Transportation and Communication, Bo, Sierra Leone: The Bo PMM Team. International Journal of Gynecology and Obstetrics, 59, S157-S164. https://doi.org/10.1016/S0020-7292(97)00161-6

[45] Tinker, A., Finn, K. and Epp, J. (2000) Improving Women's Health: Issues and Interventions. The World Bank, Health, Nutrition, and Population, Washington DC.

[46] Merson, M., Black, R. and Mills, A. (2006) International Public Health: Diseases, Programs, Systems, and Policies. Jones \& Bartlett Learning, Sudbury, MA.

[47] Ibeh, N. (2014) President Jonathan signs National Health Bill. http://www.premiumtimesng.com/news/top-news/172845-president-jonathan-signs -national-health-bill-2.html

[48] Nigeria National Health Bill (2014) (SB.215). http://www.mamaye.org.ng/sites/default/files/National\%20Health\%20Bill\%20-\%202 014\%20-\%20complete.pdf

[49] Adindu, A. (2010) Assessing and Assuring Quality of Health Care in Africa. African Journal of Medical Sciences, 3, 31-36.

https://scholar.google.com/scholar?hl=en\&q=Assessing+and+Assuring+Quality+of + Health+Care+in+Africa\&btnG=\&as_sdt=1\%2C5\&as_sdtp=

[50] Uneke, C., Ogbonna, A., Ezeoha, A., Oyibo, P., Onwe, F. and Ngwu, B. (2007) The 
Nigeria Health Sector and Human Resource Challenges. The Internet Journal of Health, 8, 1-11. https://print.ispub.com/api/0/ispub-article/6444

[51] Federal Republic of Nigeria (2007) National Human Resources for Health Strategic Plan 2008 to 2012. Federal Government of Nigeria.

http://www.who.int/workforcealliance/countries/Nigeria_HRHStrategicPlan_2008_ 2012.pdf

[52] Okeke, E., Glick, P., Abubakar, I.S., Chari, A.V., Pitchforth, E., et al. (2016) The Better Obstetrics in Rural Nigeria (BORN) Study: An Impact Evaluation of the Nigerian Midwives Service Scheme, 3ie Grantee Final Report. International Initiative for Impact Evaluation (3ie), New Delhi.

http://www.3ieimpact.org/media/filer_public/2016/07/04/gfr-ow41225-nigeria-mid wives-service.pdf

[53] Graham, H. (2004) Tackling Inequalities in Health in England: Remedying Health Disadvantages, Narrowing Health Gaps or Reducing Health Gradients? Journal of Epidemiology and Community Health, 59, 395-401.

[54] Graham, H. (2009) Health Inequalities, Social Determinants and Public Health Policy. Policy and Politics, 37, 463-479. https://doi.org/10.1332/030557309X445618

\section{List of Abbreviations}

$\begin{array}{ll}\text { ANC } & \text { Ante-Natal Care } \\ \text { BHCPF } & \text { Basic Health Care Provision Fund } \\ \text { DHS } & \text { Demographic and Health Survey } \\ \text { FGM } & \text { Female Genital Mutilation } \\ \text { LF } & \text { Logical Framework } \\ \text { MCH } & \text { Maternal and Child Health } \\ \text { MDGS } & \text { Millennium Development Goals } \\ \text { MM } & \text { Maternal Mortality } \\ \text { MMR } & \text { Maternal Mortality Ratio } \\ \text { MSS } & \text { Midwives Service Scheme } \\ \text { NHIS } & \text { National Health Insurance Scheme } \\ \text { NPHCDA } & \text { National Primary Healthcare Development Agency } \\ \text { PHC } & \text { Primary Health Centres } \\ \text { PPH } & \text { Post Partum Haemorrhage } \\ \text { SURE-P } & \text { Subsidy Re-Investment Programme } \\ \text { UNFPA } & \text { United Nations Population Fund } \\ \text { WHO } & \text { World Health Organization }\end{array}$


Submit or recommend next manuscript to SCIRP and we will provide best service for you:

Accepting pre-submission inquiries through Email, Facebook, LinkedIn, Twitter, etc. A wide selection of journals (inclusive of 9 subjects, more than 200 journals)

Providing 24-hour high-quality service

User-friendly online submission system

Fair and swift peer-review system

Efficient typesetting and proofreading procedure

Display of the result of downloads and visits, as well as the number of cited articles Maximum dissemination of your research work

Submit your manuscript at: http://papersubmission.scirp.org/

Or contact ojog@scirp.org 